\title{
An Empirical Examination of Inter-firm Capital Relationships in Mazda's Yokokai using the IDE Spatial Model
}

Makoto Sakamoto*, Satoshi Ikeda

Dept. of Computer Science and Systems Engineering, University of Miyazaki, 889-2192 Japan

Takao Ito

Graduate School of Engineering, Hiroshima University, Higashi-Hiroshima, 739-8527 Japan

Rajiv Mehta

School of Management, New Jersey Institute of Technology, 07102-1982 U.S.A

Seigo Matsuno, Shinya Tagawa

Dept. of Business Administration, Ube National College of Technology, Yamaguchi, 755-8555 Japan

Victor D. Berdonosov

Faculty of Computer Science, Komsomolsk-on-Amur State University of Technology, 691013 Russia

*Corresponding author, E-mail: sakamoto@cs.miyazaki-u.ac.jp

Tel: +81-985-58-7392, Fax: +81-985-58-7392

\begin{abstract}
Just as workflow and transactional linkages, inter-firm capital relationships are similarly known to have an impact on corporate performance. Because of the superior performance of Japanese networks known as Keiretsu, many companies have begun to recognize the importance of capital linkages whereas other companies have placed emphasis on improving coordination of managerial resources. In this paper, we review the literature on network organizations with a lens focused on examining the capital relationships in Yokokai, the Mazda's Keiretsu. Employing regression analysis, three significant indices, influence, degree, and efficiency, were selected from nine indices, including others that include dyadic redundancy, dyadic constraint, effective size, constraint, hierarchy, and density. We propose a new approach, called IDE spatial model, to calculate the strength of the inter-firm's relationships. In order to ascertain the rational inter-firm relationships, network indices and corporate performance are analyzed. Therefore, this research suggests a new perspective to examine the rational inter-firm relationship that can be used in any network organization.
\end{abstract}

Keywords: influence, degree, efficiency, the IDE spatial model, Keiretsu.

\section{Introduction}

Just as workflow and transactional linkages, inter-firm capital relationships are similarly known to have an impact on corporate performance. Because of the superior performance of Japanese networks known as Keiretsu, many companies have begun to recognize the importance of capital linkages whereas other companies 
have placed emphasis on improving coordination of managerial resources. In this paper, we propose a new approach, called IDE spatial model, to calculate the strength of the inter-firm's relationships. In order to ascertain the rational inter-firm relationships, network indices and corporate performance are analyzed. Therefore, this research suggests a new perspective to examine the rational inter-firm relationship that can be used in any network organization.

This paper is organized as follows. In Section 2, we briefly review some relevant literature of quantitative approaches of Keiretsu. Section 3 introduces the IDE spatial model. Section 4 shows the results, and discusses the implications of the results. Finally in Section 5 we conclude by a summary of this paper.

\section{Background}

One of the important factors in structural analysis, a strong tie and/or weak tie is popular way to describe the different strength of a relationship.

However, quantitative approaches are required to discover the determinants of corporate performance. Relationships among firms based on distances between their locations and the frequency of face-to-face communication among engineers in the automobile industry has been examined [1]. Moreover, Fukuoka et al. reported a new finding on relationships among member firms in Nissan's using transactions and cross shareholdings [2]. Recently Ito et al. applied graph theory to network organization analysis, and identified some characteristics such as centrality, size of network as being important facets of relationships [3]. Transactional inter-firm's relationships are the key concepts in these studies. In a Keiretsu, capital interfirm's relationship is known as cross shareholding. To the best of our knowledge, only a few studies have examined cross shareholdings from an organizational network vantage point; therefore this investigation attempts to shed light on one of the most advanced quantitative analysis using data gathered from Mazda's Yokokai Keiretsu.

\section{Method}

Many spatial paradigms, such as the IDCBI model and the DEC spatial model have been developed to discern the relationship between network indices and corporate performance. One of the key questions of this investigation is to determine if all these models are suitable for the analysis of capital network. In order to identify the factors that impact corporate performance, we employed regression analysis using three significant indices, influence, degree, and efficiency, were selected from nine indices. The others six are dyadic redundancy, dyadic constraint, effective size, constraint, hierarchy, and density. We propose a new approach, called IDE spatial model, to calculate the strength of the inter-firm’s capital relationships.

\subsection{Outline of the IDE spatial model}

Generally influence means one kind of power to affect persons or events, or causing something without any direct or discernible effort. Influence reflects the power to influence or have an impact on other member firms directly and indirectly in a network. Consequently, influence will be divided into two parts: direct influence and indirect influence. Suppose that $A$ is the matrix of the direct network, and An means the indirect influence from one firm to another firm by n steps. Then influence is calculated as follows.

$$
\begin{aligned}
& T=A+R=A+A^{2}+A^{3}+\cdots+A^{n} \\
& =A(I-A)^{-1}
\end{aligned}
$$

where

T: Total influence;

A: direct influence;

R: indirect influence;

I: Identity matrix.

An integral index known as centrality has many facets that include degree, closeness, and betweenness. Degree expresses a firm's potential communication activity. In cross shareholding network, degree includes two categories: in-degree and out-degree, because cross shareholding networks are considered to be asymmetric organizations. In-degree refers to a firm accept investment from other member firms, whereas outdegree reflects a firm that only buy stocks of other firms within the network. Degree is calculated as below.

$$
\begin{aligned}
C_{D}\left(p_{k}\right)= & =\sum_{i=1}^{n} a\left(p_{i}, p_{k}\right) \\
& i=1,2, \cdots, n ; \quad k=1,2, \cdots, n
\end{aligned}
$$

where

$\mathrm{a}\left(\mathrm{p}_{\mathrm{i}}, \mathrm{p}_{\mathrm{k}}\right)=1$; if and only if $\mathrm{p}_{\mathrm{i}}$ and $\mathrm{p}_{\mathrm{k}}$ are connected by a line

$\mathrm{a}(\mathrm{pi}, \mathrm{pk})=0$; otherwise 
In this paper, percent data of inter-firm's transactions are collected from Yokokai.

Efficiency is another important index. Effective size of the network is the number of alters that ego has, minus the average number of ties that each alter has to other alters. Suppose that A has ties to three other actors. Further, suppose that none of these three has ties to any of the others. Thus the effective size of ego's network is three. Alternatively, suppose that A has ties to three others, and that all of the others are tied to one another. A's network size is three, but the ties are "redundant" because A can reach all three neighbors by reaching any one of them. The average degree of the others in this case is 2 (each alter is tied to two other alters). Therefore, the effective size of the network is its actual size, i.e., 3, reduced by its redundancy, i.e., 2, to yield an efficient size of 1 . Efficiency expresses the effective size of ego's network by its actual size. That is, what proportion of ego's ties to its neighborhood is "nonredundant”? Thus, efficiency tells us how much impact ego is getting for each unit invested in using ties. A firm can be effective without being efficient; and an actor can be efficient without being effective.

\subsection{Data collection and visualization}

In order to measure influence, degree, and efficiency of each firm in Yokokai, cross shareholding data in the Yokokai Keiretsu in 1997 and 2004 have been collected from our interviews and the publications of the Japan Auto Parts Industries Association and Automotive Parts Publishing Company [4].

In 1997, 53 financial institutions, 190 parts suppliers, and 11 carmakers are included in Yokokai. The detailed information of the numbers of financial institutions, parts-supplies, and carmakers in Mazda' cross shareholdings network in 1997 and 2004 are shown in Table 1.

In this paper, a singleton, which can be found in any network, is defined as a firm that exists independently, without any relationship with other firms. Therefore, a singleton generally is an isolated firm in a given network. In 1997, 132 singletons including 26 financial institutions, 105 parts-suppliers, and 1 carmaker have been found. In 2004, 1 financial institution, 120 partssuppliers, and 2 carmakers are singletons. All of the singletons have been removed in this paper because the number of singletons has no any impact on the calculation results.

Table 1 Numbers of financial institutions, parts suppliers and carmakers in Yokokai in 1997 and 2004

\begin{tabular}{|l|r|r|}
\hline & 1997 & \multicolumn{1}{|c|}{2004} \\
\hline Financial Institutions & 53 & 36 \\
\hline Parts-suppliers & 190 & 177 \\
\hline Carmakers & 11 & 11 \\
\hline Total & 254 & 224 \\
\hline
\end{tabular}

The cross shareholdings relationships among the companies were identified through three dimensional modeling. A bar shows the percentage of the transaction between each pairs of firms. The three dimensional capital inter-firm relationships in Yokokai are depicted in Figure 1 and 2 respectively.

The cross shareholdings relationships among the companies were identified through three dimensional modeling. A bar shows the percentage of the transaction between each pairs of firms. The three dimensional inter-firm capital relationships in Yokokai are shown in Figure 1 and 2 respectively.

Compared with Figure 1, we find that the interactivity between financial institutions and parts-suppliers is lower, whereas the interactivity between parts suppliers is higher. The reason is that the interactive relationship among financial institutions, suppliers and carmakers changed rapidly with the varying of economic environment. For suppliers, the control from carmakers is becoming looser than before. Now suppliers can more easily forge a new capital relationship with other firms.

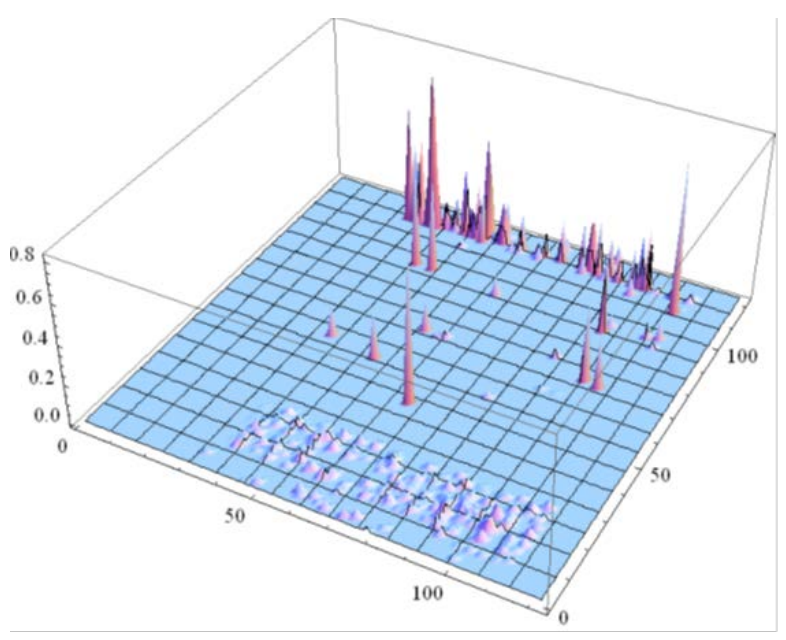

Figure 1 Inter-firm’s capital network in 1997 


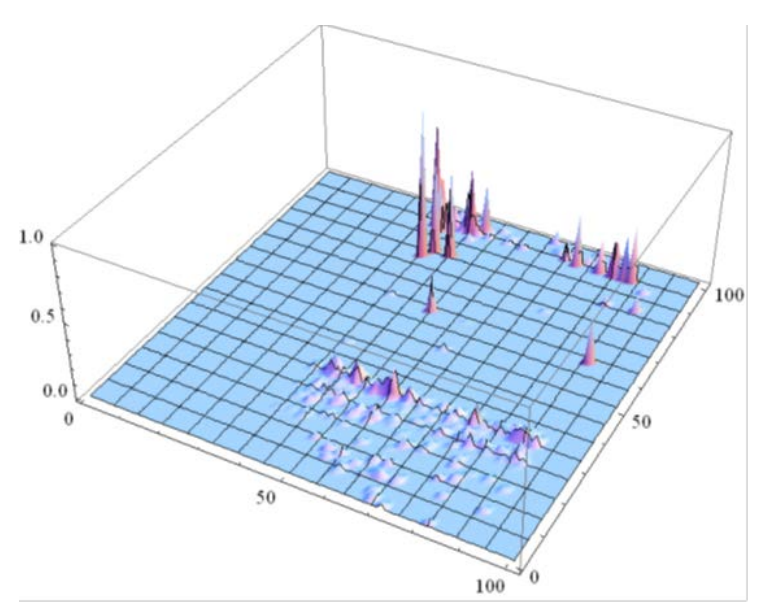

Figure 2 Inter-firm’s capital network in 2004

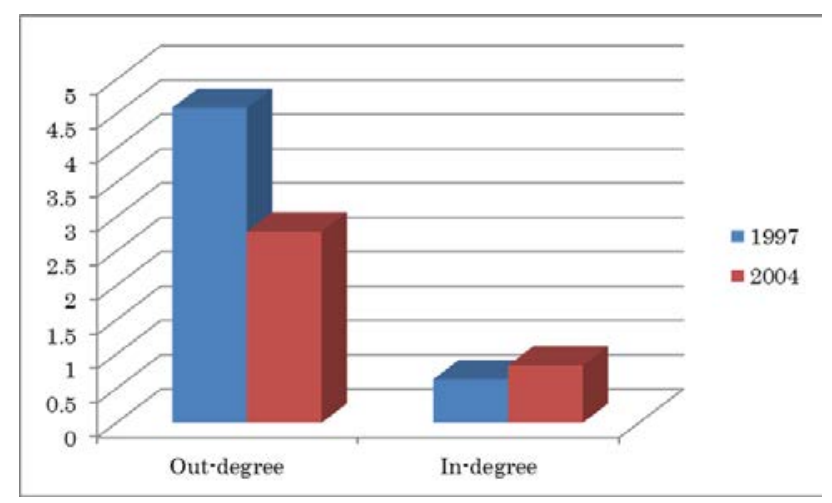

Figure 3 Out-degree and in-degree in 1997 and 2004.

\section{Results and discussions}

\subsection{Centrality changes}

In an asymmetric network, degree can be divided into two parts: out-degree and in-degree. The result of the out-degree and in-degree of the whole cross shareholdings is shown in Figure 3.

The out-degree in 2004 is lower than that in 1997 but the in-degree in 2004 is higher than that in 1997. Lower centrality means that much more companies invest their money to buy parts suppliers they interested. In other word, parts supplier can accept much more different companies' investment without permission from the top firm of their Keiretsu. Especially the dramatically change between out-degree and in-degree inflects the structure changes happened in Yokokai.

\subsection{Data collection and visualization}

We calculated partial correlation coefficient of the nine indices in multiple regression model, and found density, effective size and other 4 indices are not significant. Thus we removed those 6 variables and re-estimated the regression model. The results in 1997 are shown in Table 2.

Table 2 Results of the variance analysis

\begin{tabular}{|l|c|c|c|c|}
\hline & $\begin{array}{c}\text { Sum of } \\
\text { Squares }\end{array}$ & $\begin{array}{c}\text { Degree of } \\
\text { Freedom }\end{array}$ & $\begin{array}{c}\text { Mean } \\
\text { Square }\end{array}$ & F Test \\
\hline Total & $4.239 \mathrm{E}+11$ & 61 & & 36.721 \\
\hline Regression & $2.777 \mathrm{E}+11$ & 3 & $9.257 \mathrm{E}+10$ & Prob. \\
\hline Residual & $1.462 \mathrm{E}+11$ & 58 & $2.521 \mathrm{E}+09$ & 0.000 \\
\hline
\end{tabular}

Coefficient of determination: 0.65510

Multiple correlation coefficient: 0.80938

Adjusted R-square: 0.79829

AIC: $1,521.98$

DW ratio: 2.5382

As shown in Table 1, the coefficient of determination is 0.65510 , and DW ratio is 2.5382 , and the probability is 0.000 . Therefore, the regression model is significant. The estimation of regression coefficients is shown in Table 3.

Table 3 Estimation of regression coefficients

\begin{tabular}{|l|r|r|r|r|}
\hline & Influence & \multicolumn{1}{c|}{ Degree } & Efficiency & \multicolumn{1}{c|}{ Intercept } \\
\hline $\begin{array}{l}\text { Partial } \\
\text { regression } \\
\text { coefficient }\end{array}$ & $4.17 \mathrm{E}+7$ & $-7.300 \mathrm{E}+4$ & $5.575 \mathrm{E}+5$ & $-5.509 \mathrm{E}+5$ \\
\hline $\begin{array}{l}\text { Standard } \\
\text { coefficient }\end{array}$ & 82.896 & -82.398 & 0.289 & 0.000 \\
\hline T value & 8.536 & -8.487 & 3.465 & -3.455 \\
\hline $\begin{array}{l}\text { Degree of } \\
\text { Freedom }\end{array}$ & 58 & 58 & 58 & 58 \\
\hline Prob. & 0.000 & 0.000 & 0.001 & 0.001 \\
\hline $\begin{array}{l}\text { Correlation } \\
\text { coefficient }\end{array}$ & 0.4756 & 0.470 & -0.018 & \\
\hline $\begin{array}{l}\text { Partial } \\
\text { correlation } \\
\text { coefficient }\end{array}$ & 0.746 & -0.744 & 0.414 & \\
\hline
\end{tabular}

The estimation of regression coefficients in 2004 has been calculated also. Based upon Table 2 and the calculation of 2004, influence, degree, and efficiency are significant. Degree is negative, while influence and efficiency are positive. Degree is an index of number of stockholdings, and influence is an index of structural positions, then the hypothesis of "better structural position, higher performance” is upheld. 
The number of influence is decreasing. And the number of degree and efficiency are increasing. It means that the importance of structural position is still effective, but the capital relationship with other firms and the managing cost of investment is becoming more and more important because of the membership keiretsu is loosening..

\section{Conclusion and future works}

In this paper, the new approach of IDE analysis is proposed, and its validity is proved. We ascertained that (1) the centrality of Keiretsu is becoming low, (2) not all network indices, only influence, degree, and efficiency has an impact on profits. (3) The importance of influence is becoming lower, and the degree and efficiency is becoming higher due to the trend in the loosening of Keiretsu. However, additional research advocated developing our knowledge on rational capital relationships with other parts suppliers.

Acknowledgment: This research was partially supported by the Japan Society for the Promotion of Science, Grant-in-Aid for Scientific Research (C) 24510217.

\section{References}

1. Dyer H. J. (1996) "Specialized Supplier Networks as a Source of Competitive Advantage: Evidence from the Auto Industry”, Strategic Management Journal, Vol. 17, 271-291

2. Fukuoka S., Ito T., Passerini K. and Sakamoto M. (2006) An Analysis between Transaction and Cross Shareholdings in the Keiretsu of Nissan, Managing Information in the Digital Economy Issues \& Solutions, 163-169, IBIMA International Conference, Bonn Germany

3. Ito T., Tagawa S., Matsuno S., Uchida Y., Sakamoto M., Ikeda S., Mehta R. (2013) An Analysis of Network Structure in Mazda's Yokokai using the DEC Spatial Model, Proceedings of the 2013 International Conference on Business Administration, Marketing, and Economics (MAME 2013), Recent Advances in Business Administration, Marketing and Economics, pp.77-81, September 28-30, 2013, Venice, Italy

4. JAPIA\&APPC $(1997,2004)$, Japanese Automotive Parts Industry, Automotive Parts Publishing Company, (Japanese Edition) 